\title{
Article \\ Platelet Inhibition by Low-Dose Acetylsalicylic Acid Reduces Neuroinflammation in an Animal Model of Multiple Sclerosis
}

\author{
Anna Vogelsang ${ }^{1, *,+}$, Susann Eichler ${ }^{1, \dagger}{ }^{,}$Niklas Huntemann ${ }^{1,2} \oplus$, Lars Masanneck ${ }^{1,2}$, Hannes Böhnlein ${ }^{1}$, \\ Lisa Schüngel ${ }^{3}$, Alice Willison ${ }^{4}$, Karin Loser ${ }^{5}$, , Bernhard Nieswandt ${ }^{6}$, Beate E. Kehrel ${ }^{3}$, Alexander Zarbock ${ }^{3}$, \\ Kerstin Göbel ${ }^{1}$ (I) and Sven G. Meuth ${ }^{2}$
}

Citation: Vogelsang, A.; Eichler, S. Huntemann, N.; Masanneck, L.; Böhnlein, H.; Schüngel, L.; Willison, A.; Loser, K.; Nieswandt, B.; Kehrel, B.E.; et al. Platelet Inhibition by Low-Dose Acetylsalicylic Acid Reduces Neuroinflammation in an Animal Model of Multiple Sclerosis. Int. J. Mol. Sci. 2021, 22, 9915 https://doi.org/10.3390/ ijms22189915

Academic Editor: Elisabetta Coppi

Received: 10 August 2021

Accepted: 10 September 2021

Published: 14 September 2021

Publisher's Note: MDPI stays neutral with regard to jurisdictional claims in published maps and institutional affiliations.

Copyright: (c) 2021 by the authors. Licensee MDPI, Basel, Switzerland. This article is an open access article distributed under the terms and conditions of the Creative Commons Attribution (CC BY) license (https:/ / creativecommons.org/licenses/by/ $4.0 /)$.
1 Department of Neurology with Institute of Translational Neurology, University Hospital Münster, 48149 Münster, Germany; eichlers@uni-muenster.de (S.E.); niklas.huntemann@uni-muenster.de (N.H.); lars.masanneck@uni-muenster.de (L.M.); hannes.boehnlein@web.de (H.B.); kerstin.goebel@ukmuenster.de (K.G.)

2 Department of Neurology, University Hospital Düsseldorf, 40225 Düsseldorf, Germany; meuth@uni-duesseldorf.de

3 Department of Anesthesiology, Intensive Care and Pain Medicine, University Hospital Münster, 48149 Münster, Germany; lisa.schuengel@uni-muenster.de (L.S.); kehrel@uni-muenster.de (B.E.K.); zarbock@uni-muenster.de (A.Z.)

4 The Northern Foundation School, Newcastle-upon-Tyne University Hospitals, Newcastle-upon-Tyne NE15 8NY, UK; alice.willison@newcastle.ac.uk

5 Department of Human Medicine, Institute of Immunology, Carl von Ossietzky University Oldenburg, 26129 Oldenburg, Germany; karin.loser@uol.de

6 Rudolf Virchow Center, Research Center for Experimental Biomedicine, University of Würzburg, 97080 Würzburg, Germany; bernhard.nieswandt@virchow.uni-wuerzburg.de

* Correspondence: anna.vogelsang@ukmuenster.de

+ These authors contributed equally to this work.

\begin{abstract}
Aside from the established immune-mediated etiology of multiple sclerosis (MS), compelling evidence implicates platelets as important players in disease pathogenesis. Specifically, numerous studies have highlighted that activated platelets promote the central nervous system (CNS)-directed adaptive immune response early in the disease course. Platelets, therefore, present a novel opportunity for modulating the neuroinflammatory process that characterizes MS. We hypothesized that the well-known antiplatelet agent acetylsalicylic acid (ASA) could inhibit neuroinflammation by affecting platelets if applied at low-dose and investigated its effect during experimental autoimmune encephalomyelitis (EAE) as a model to study MS. We found that oral administration of low-dose ASA alleviates symptoms of EAE accompanied by reduced inflammatory infiltrates and less extensive demyelination. Remarkably, the percentage of CNS-infiltrated CD4 ${ }^{+} \mathrm{T}$ cells, the major drivers of neuroinflammation, was decreased to $40.98 \pm 3.28 \%$ in ASA-treated mice compared to $56.11 \pm 1.46 \%$ in control animals at the disease maximum as revealed by flow cytometry. More interestingly, plasma levels of thromboxane $\mathrm{A}_{2}$ were decreased, while concentrations of platelet factor 4 and glycoprotein VI were not affected by low-dose ASA treatment. Overall, we demonstrate that low-dose ASA could ameliorate the platelet-dependent neuroinflammatory response in vivo, thus indicating a potential treatment approach for MS.
\end{abstract}

Keywords: acetylsalicylic acid; experimental autoimmune encephalomyelitis; platelets; multiple sclerosis; thromboxane; glycoprotein VI; platelet factor 4

\section{Introduction}

Multiple sclerosis (MS) is the most common immune-mediated inflammatory disease of the central nervous system (CNS) [1,2]. It is generally accepted that an aberrant immune response results in demyelination and axonal loss within the CNS, leading to neurological disability [3]. Although the etiology of MS is not fully understood, advances 
in our understanding of the immune mechanisms that characterize the relapsing and inflammatory stages of MS have led to therapeutic options with distinct immunomodulatory or immunosuppressive effects in the past 30 years. Thus, the currently available diseasemodifying drugs for treating MS mainly target lymphocytes, including consequences on $\mathrm{T}$ cell activation, as well as on peripheral T lymphocyte trafficking into the CNS $[4,5]$. While various treatments reduce the frequency and severity of relapses, they cannot cure the disease, emphasizing that other, not typically considered, components of the immune system might also be involved. There is evidence that interaction between platelets and immunity fosters aberrant immune responses in MS and experimental autoimmune encephalomyelitis (EAE), an animal model that mimics pathological hallmarks observed in MS [6]. In EAE, platelets were found accumulating in the CNS parenchyma, thereby amplifying the (neuro)inflammatory response. As already demonstrated for cells of the immune system, platelets, as part of the coagulation system, seem to infiltrate the CNS and aggregate within MS and EAE lesions [6-11]. Of note, platelet depletion during the effector phase of EAE reduces the disease severity and is associated with a reduction in CNS-infiltrating immune cells from the periphery $[6,10]$. Furthermore, recent studies demonstrated that platelets are chronically activated in the early stages of EAE [8]. Platelets obtained from MS patients, especially in relapsing-remitting and secondary progressive MS, show a chronically activated status [12-14]. Interestingly, MS patients showed an increased risk of vascular disorders, such as ischemic stroke and myocardial infarction [15-17]. The critical role of platelets in MS and EAE pathophysiology still needs to be clarified in more detail.

One of the most widely used antiplatelet medications is the anti-inflammatory drug acetylsalicylic acid (ASA; also known as aspirin). ASA has many uses, one of which is to diminish platelet activation and aggregation, thereby limiting thrombus formation [18]. The mechanism of action of ASA involves irreversible acetylation and subsequent inactivation of cyclooxygenase (COX)- 1 , thus inhibiting the formation of thromboxane $\mathrm{A}_{2}\left(\mathrm{TxA}_{2}\right)$, a key factor in platelet aggregation during primary hemostasis [19]. At low doses, ASA can be taken life-long by patients and is, in contrast to high-doses, effective by selective inhibition of platelet aggregation [20], making it a useful instrument to prevent occlusive vascular events, such as ischemic stroke or myocardial infarction [21]. High doses of ASA do not exhibit an increased antithrombotic effect compared to low doses of ASA and, due to the risk of bleeding, high-dose ASA is only used for short-term analgesia in clinical practice $[22,23]$. Of note, high-dose ASA also results in the inhibition of endogenous prostacyclin biosynthesis [24]. Due to the irreversible inhibition of COX-1, the therapeutic effect of ASA is dependent on platelet lifespan and synthesis. Further, ASA affects the coagulation cascade and fibrinolysis by reducing thrombin levels at sites of microvascular injury and by impairing fibrin clotting $[25,26]$. Of particular relevance, ASA-induced inhibition of $\mathrm{TxA}_{2}$ synthesis systemically blocks platelet cluster of differentiation (CD)40L release $[27,28]$, a pro-thrombotic and proinflammatory protein that was shown to be upregulated in MS patients [29-31].

Few studies have examined the effect of ASA on EAE disease activity. Early data, published in 1949, indicated that high-dose prophylactic treatment with sodium salicylate, the precursor of ASA, reduced EAE disease severity [32]. In an EAE model using Lewis rats, treatment with sodium salicylate delayed disease onset and reduced clinical signs of neuroinflammation [33]. In addition, Mondal et al. demonstrate that ASA impedes EAE disease progression protecting regulatory $\mathrm{T}$ cells and suppressing proinflammatory $\mathrm{T}$ helper $\left(\mathrm{T}_{\mathrm{H}}\right) 1$ and $\mathrm{T}_{\mathrm{H}} 17$ cells in a relapsing-remitting EAE model [34]. More recent studies have examined the role of COX-1 and COX-2 in EAE. Naproxen, an inhibitor of COX-1 and -2, was shown to delay the onset of EAE symptoms and alleviate disease severity [35]. Here, we investigated the therapeutic potential of low-dose ASA under pathophysiological conditions in vivo. 


\section{Results}

\subsection{ASA Significantly Ameliorates Clinical Symptoms of EAE}

To elucidate the role of ASA during neuroinflammation, mice subjected to EAE were orally treated daily with $3 \mathrm{mg} / \mathrm{kg}$ body weight (BW) ASA ( $\mathrm{ASA}_{\text {low }}$ ), $30 \mathrm{mg} / \mathrm{kg}$ BW ASA $\left(\mathrm{ASA}_{\text {high }}\right)$ or a vehicle control for a period of 30 days, beginning on the day of immunization. Interestingly, prophylactic treatment with both high- and low-dose ASA significantly alleviated disease severity and cumulative (cum.) EAE scores but no difference could be detected between low and high doses of ASA (Figure 1B,C). Disease onset was not affected by ASA treatment (Figure 1D). Disease incidence was the same for all groups, with all mice used in experimentation showing EAE symptoms (data not shown). Histological examination of sections of the lumbar spinal cord, which is the main site of neuroinflammatory processes in active EAE [36], showed reduced CNS infiltration, as well as less demyelination (Figure 1E-H). However, there was no significant difference in the number of activated microglia and macrophages visualized by ionized calcium-binding adaptor molecule 1 (lba-1) between all experimental groups (Figure S1B). Single stainings are given for all fluorochromes (Figure S1A,C).

A

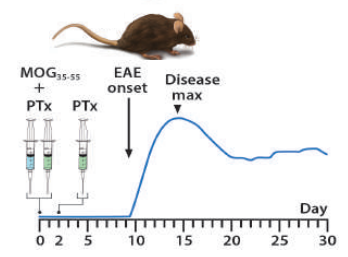

B

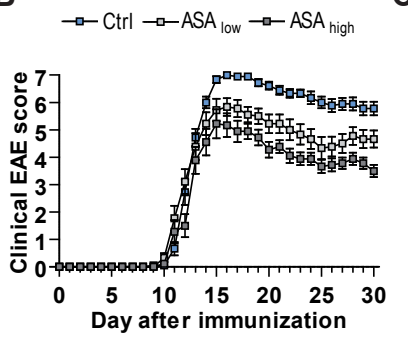

C
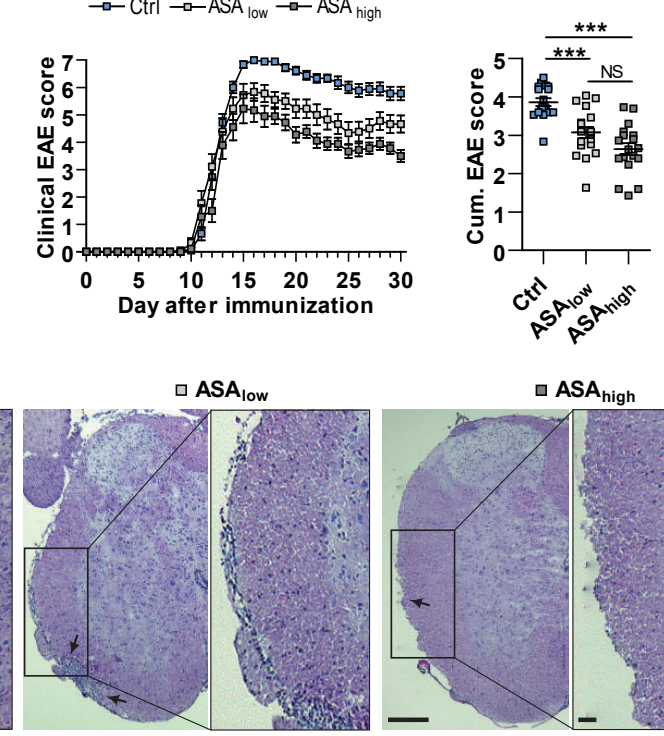

$\square$ ASA $_{\text {low }}$

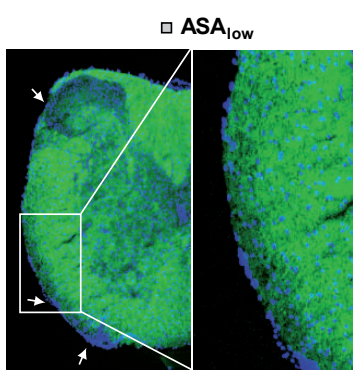

$\square$ ASA $_{\text {high }}$
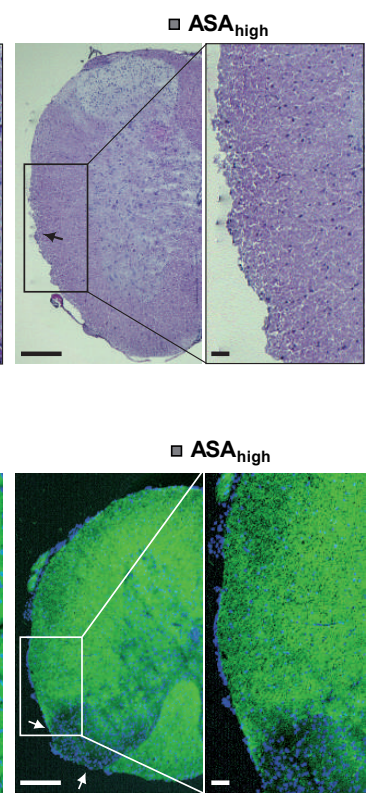

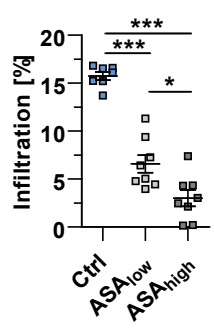

H
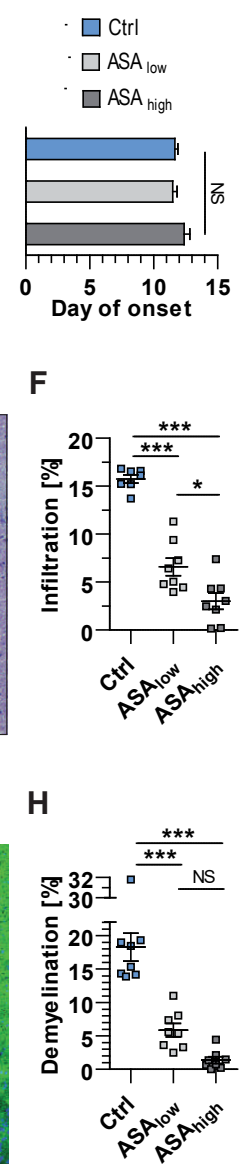

Figure 1. Acetylsalicylic acid (ASA) reduces the clinical disease activity of experimental autoimmune encephalomyelitis (EAE). (A) Experimental overview of active EAE induction illustrating the time points of myelin oligodendrocyte glycoprotein (MOG) $35-55$ peptide and pertussis toxin (PTx) administration. (B) The clinical EAE scores and (C) the cumulative (cum.) scores of $\mathrm{MOG}_{35-55}$-immunized mice are presented for mice receiving a vehicle as control (Ctrl), $3 \mathrm{mg} / \mathrm{kg}$ body weight (BW) ASA $\left(\mathrm{ASA}_{\text {low }}\right.$ ) or $30 \mathrm{mg} / \mathrm{kg} \mathrm{BW}$ ASA ( $\mathrm{ASA}_{\text {high }}$ ) daily, beginning on the day of immunization. (D) The average day of disease onset is presented for each experimental group. (E-H) Lumbar spinal cord sections isolated at disease maximum (day 16) were histologically analyzed using hematoxylin and 
eosin $(\mathbf{H}, \mathbf{E}),(\mathbf{E}, \mathbf{F})$ as well as myelin staining (Myelin) $(\mathbf{G}, \mathbf{H})$. For the visualization of cell nuclei, sections were stained with $4^{\prime}$,6-diamidino-2-phenylindole (DAPI), of which representative images are shown (scale bar: $200 \mu \mathrm{m}$; close-up scale bar: $100 \mu \mathrm{m}$ ). Arrows indicate areas with extensive infiltration $(\mathbf{E})$ or demyelination $(\mathbf{G})$ and quantitative analyses are shown $(\mathbf{F}, \mathbf{H})$. Data were analyzed by two-way analysis of variance (ANOVA; 18 vs. 18 vs. 18 mice; 3 independent experiments; (B)) or Mann-Whitney U-test $(\mathbf{C}, \mathbf{D}, \mathbf{F}, \mathbf{H})$. Each symbol represents an individual mouse $(\mathbf{C}, \mathbf{F}, \mathbf{H})$. The level of significance was labeled as NS (not significant), ${ }^{*}$ probability $p<0.05$ or ${ }^{* * *} p<0.001$.

\subsection{ASA Reduces the Infiltration of $C D 4^{+} T$ Lymphocytes into the CNS}

Further investigations using flow cytometry showed a reduction of peripheral infiltrates within the CNS of both ASA-treated mice, as indicated by amelioration of invaded CD45 high cells (Figure 2B). The total number of lymphocytes was also reduced in both ASA-treated mice, while monocytes/macrophages, dendritic cells and microglia were not significantly different (Figure 2C). Since EAE lesions are dominated by infiltrated proinflammatory T lymphocytes [36], we investigated the proportion of lymphocyte cells within the inflammatory infiltrates. Indeed, the percentages of $\mathrm{CD} 4^{+} \mathrm{T}$ cells, $\mathrm{CD} 8^{+} \mathrm{T}$ cells, and also $\mathrm{B}$ cells were significantly reduced in mice treated with a low or high dose of ASA (Figure $2 \mathrm{D}, \mathrm{E}$ ). The proportion of infiltrated $\mathrm{CD} 4^{+} \mathrm{T}$ cells, for instance, was reduced to $40.98 \pm 3.28 \%$ in mice treated with low-dose ASA compared to $56.11 \pm 1.46 \%$ in control mice (Figure 2D). Since the depletion of platelets during the effector phase is associated with an improved EAE course [6], we determined the number of platelets present in the CNS of EAE affected mice. Indeed, we did not find significant differences in the platelet counts within the inflamed CNS at the disease maximum between the experimental groups. Interestingly, no significant difference between low- or high-dose administration of ASA was observed in terms of cum. EAE scores, the degree of demyelination, the total number of CNS infiltrating leukocytes, lymphocytes, $\mathrm{CD}^{+} \mathrm{T}^{\mathrm{T}}$ cells, $\mathrm{CD}^{+} \mathrm{T}$ cells and $\mathrm{B}$ cells.

A

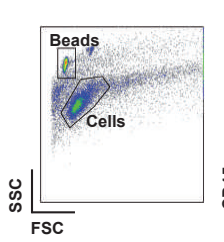

D

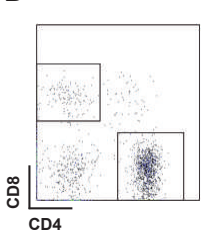

$\mathbf{F}$

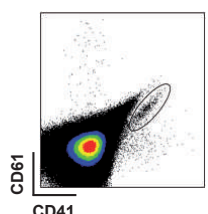

B
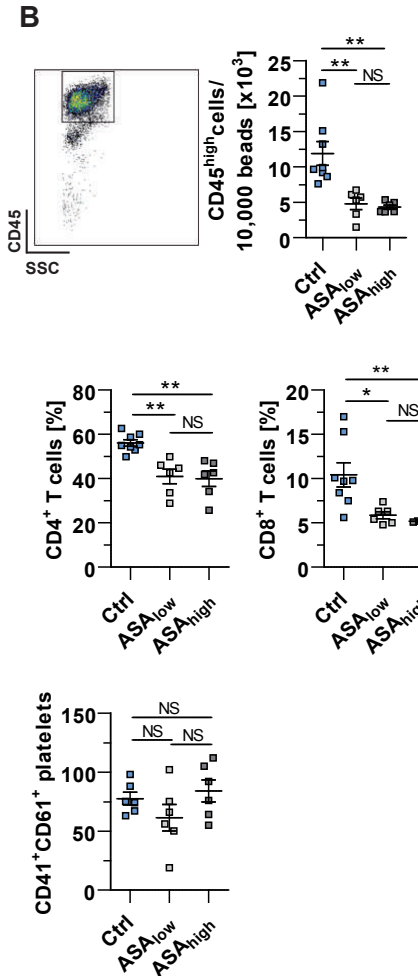

c

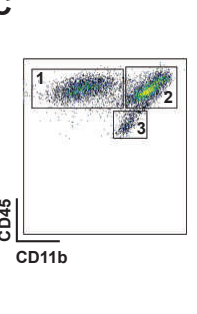

E
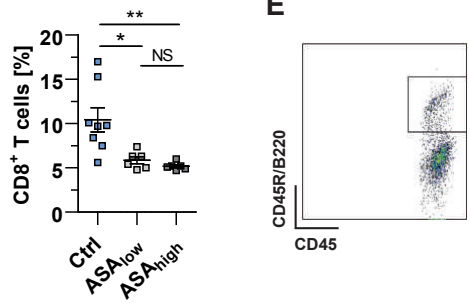

a Ctrl a ASA low a ASA high

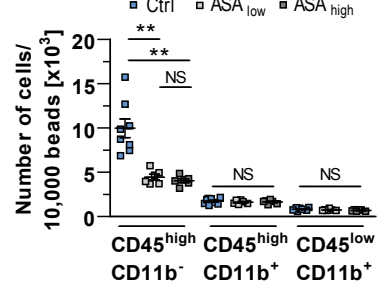

Figure 2. Central nervous system (CNS) immune cell infiltration is reduced by low-dose ASA administration. (A) CNS-infiltrating immune cells of all experimental groups were analyzed at disea- 
se maximum using flow cytometry. (B) The number of clusters of differentiation CD45 high cells, representing infiltrated peripheral immune cells, was quantified in relation to reference beads. (C) For further insights, infiltrated cells were analyzed for $\mathrm{CD} 45^{\text {high }} \mathrm{CD} 11 \mathrm{~b}-(1$, indicating peripheral lymphoid cells), $\mathrm{CD} 45^{\text {high }} \mathrm{CD} 11 \mathrm{~b}^{+}\left(2\right.$, indicating peripheral myeloid cells) and $\mathrm{CD} 45^{\text {low }} \mathrm{CD} 11 \mathrm{~b}^{+}$cells (3, indicating resident microglial cells) relative to reference beads. $(\mathbf{D}, \mathbf{E})$ For a broader characterization of infiltrating lymphoid cells, the proportions of $\mathrm{CD}^{+} \mathrm{CD}^{+}, \mathrm{CD}^{+} \mathrm{CD} 3^{+}$and $\mathrm{CD} 45 \mathrm{R} / \mathrm{B} 220^{+}$cells were determined. (F) Platelet-rich supernatants isolated from CNS homogenates were stained for CD41 and CD61 and examined by flow cytometry for quantification of platelets present in the CNS. A representative dot plot is shown, and total numbers of $\mathrm{CD} 41^{+} \mathrm{CD} 61^{+}$cells were calculated. Data were analyzed by Mann-Whitney U-test (B-F), and each symbol represents an individual mouse (8 vs. 6 vs. 6 mice; 2 independent experiments; B-F). The level of significance was labeled as NS, ${ }^{*} p<0.05$ or ${ }^{* *} p<0.01$. FSC, forward scatter; SSC, side scatter.

\section{3. $\mathrm{Tx} \mathrm{A}_{2}$ Synthesis Is Reduced by Low-Dose ASA Treatment}

To establish the underlying mechanism of low-dose ASA-induced platelet-mediated inhibition of neuroinflammation, soluble factors were measured using enzyme-linked immunosorbent assays in plasma of naïve untreated as well as immunized EAE mice treated with low-dose ASA or vehicle. The production of thromboxane $B_{2}$, the stable hydration product and, therefore, the representative for $\mathrm{TxA}_{2}$ levels, by platelets, was significantly lowered in mice receiving low-dose ASA compared to vehicle-treated EAE mice (Figure 3A). Since platelet factor 4 (PF4) is a well-known proinflammatory platelet alpha-granule protein, we investigated plasma PF4 level changes during neuroinflammation. However, in agreement with a former study, we found no effect of ASA treatment on PF4 plasma levels [37]. GPVI is one of the most important platelet collagen receptors, and soluble GPVI is rapidly proteolytically cleaved by $\mathrm{TxA}_{2}$-induced matrix metalloproteinases (MMP) [38]. However, no significant differences between ASA-treated or control mice were found for soluble PF4 or GPVI plasma levels (Figure 3B,C). Interestingly, soluble GPVI levels were significantly increased in EAE mice at the disease maximum (Figure 3C), implying a potential contribution of GPVI to EAE pathology. To this end, we investigated the GPVI-related effects on neuroinflammation in EAE. The clinical EAE scores showed a minor reduction in mice deficient for GPVI (GPVI-/-) (Figure S2A). The cum. EAE scores between $\mathrm{WT}$ and $\mathrm{GPVI}^{-/-}$mice were not altered (Figure S2B). Neither disease incidence nor onset differed between the experimental groups (Figure S2C,D).

A

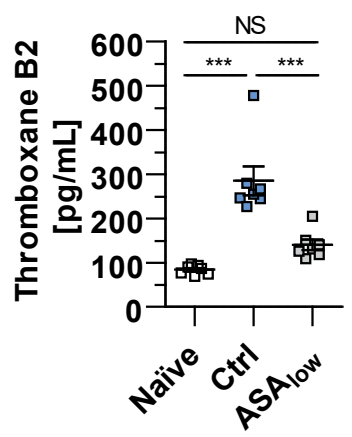

B

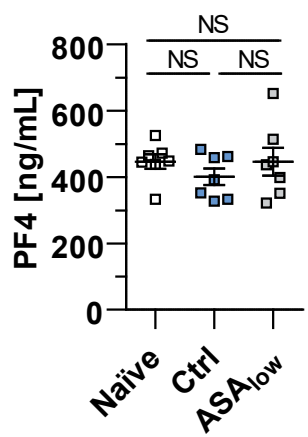

C

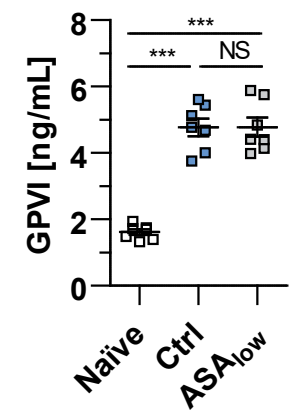

Figure 3. Administration of low-dose ASA reduces the synthesis of thromboxane B2 during neuroinflammation. (A-C) The levels of thromboxane B2 (A), platelet factor 4 (PF4) (B) and glycoprotein VI (GPVI) (C) were determined using enzyme-linked immunosorbent assays. Therefore, blood plasma was obtained from naïve mice (Naïve), from vehicle-treated mice at EAE disease maximum (Ctrl) and mice treated with $3 \mathrm{mg} / \mathrm{kg}$ BW of ASA $\left(\mathrm{ASA}_{\text {low }}\right)$ at EAE disease maximum. Data were analyzed by Mann-Whitney U-test (7 vs. 7 vs. 7 mice; 2 independent experiments). Each symbol represents an individual animal. The level of significance was labeled as NS, ${ }^{* * *} p<0.001$. 


\subsection{Therapeutic Treatment with Low-Dose ASA Improves the Clinical Outcome of EAE}

ASA was also administered therapeutically to mice and was started on the day of disease onset. Clinical EAE scores and cum. EAE scores were reduced by low-dose ASA treatment (Figure 4A,B). Since the ASA treatment was started on disease onset, the incidence and day of disease onset were displayed as an additional methodological control factor. In agreement, the disease incidence was not altered and was $100 \%$ as all mice developed EAE symptoms (Figure $4 \mathrm{C}$ ). The disease onset was also not affected by treatment with low-dose ASA (Figure 4D).

A

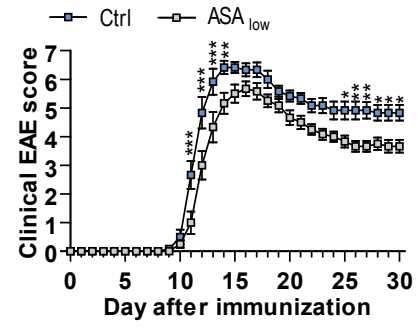

B

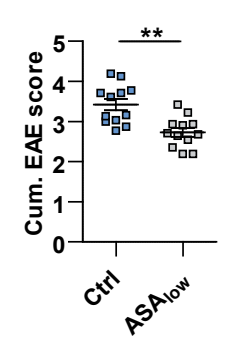

C

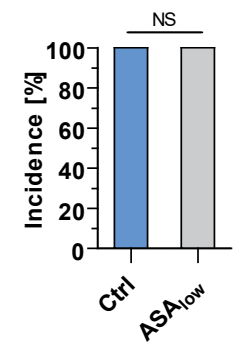

D

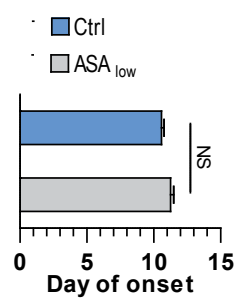

Figure 4. Therapeutic administration of low-dose ASA ameliorates clinical symptoms of EAE. $(A, B)$ Daily clinical EAE scores of $M_{35}$-55-immunized mice are presented (A) and the cum. EAE scores are calculated for vehicle (Ctrl) and low-dose ASA-treated mice $\left(\mathrm{ASA}_{\text {low }}\right)(\mathbf{B})$. Mice were treated with ASA or vehicle from the day of clinical EAE onset. $(\mathbf{C}, \mathbf{D})$ Disease incidence $(\mathbf{C})$ and the average day of disease onset after immunization (D) are shown. Data were analyzed by two-way ANOVA ( $n=12$ vs. 12 mice; two independent experiments; (A)) or Mann-Whitney U-test (B-D). Each symbol represents an individual mouse (B). The level of significance was labeled as NS, ${ }^{*} p<$ $0.05,{ }^{* *} p<0.01$ or ${ }^{* * *} p<0.001$.

These data suggest that the application of low-dose ASA is a promising approach to abrogate the neuroinflammatory processes mediated by activated platelets responsible for MS pathogenesis. Low-dose ASA is of particular interest due to its low bleeding risk and well-tolerated side effects, but with a comparable impact as high-dose ASA on neuroinflammation.

\section{Discussion}

Using established therapies for new indications, instead of searching for novel therapeutic approaches for disease pathologies that are not yet fully understood, is known as "repurposing". This method is becoming increasingly popular in translational science, as it has the clear advantage of side effects already well-studied in human clinical trials, thereby increasing patient safety and accelerating the approval process for new indications.

In the present study, we demonstrate that the pharmacologic blockade of platelets using both low- and high-dose ASA, a well-known antiplatelet drug, renders EAE mice less susceptible to neuroinflammation. Oral treatment with ASA was associated with a reduction in disease severity, a lessened degree of demyelination and decreased immune cell infiltration into the CNS. These findings indicate that there are meaningful relationships between low-dose ASA-induced platelet inhibition and amelioration of disease pathogenesis. We tested two doses of ASA and found that low-dose ASA resulted in an equal reduction in EAE progression, cum. EAE scores, the extent of demyelination and CNS infiltration by immune cells compared to the high-dose ASA treatment. Consequently, low-dose ASA has an equal anti-inflammatory effect on the progression of neuroinflammation while having a much better side effect profile. One explanation for this could be that the inactivation of COX-1 by ASA is irreversible, and even low-dose ASA can reach an inactivation saturation phase [19].

The effect of low-dose ASA cannot be explained by a deficiency of infiltrated platelets because flow cytometric analysis showed no significant difference in the number of infil- 
trated platelets in the CNS of ASA-treated mice compared with control mice. We suggest that the beneficial effect of ASA treatment during EAE is mediated by altered platelet function. In line with the results from our chronic EAE model, Mondal et al. demonstrated a promising effect of low-dose ASA in a relapsing-remitting EAE model. In addition, Modal et al. investigated the EAE course in a chronic EAE model and found the same trend supported by our data. However, they focused on EAE course progression and performed experiments on the relapsing-remitting model [34]. The contribution of platelets has to be investigated in a relapsing-remitting model of EAE and is not well understood.

Examination of the mechanism of platelet inhibition by ASA demonstrated a significant reduction of $\mathrm{TxA}_{2}$ and recruitment of $\mathrm{CD}^{+} \mathrm{T}$ cells in ASA-treated mice. Furthermore, $\mathrm{TxA}_{2}$ may mediate the interaction between platelet and lymphocyte or endothelial cell activation. Interestingly, Kabashima et al. have shown in mice that naïve $\mathrm{T}$ cells express the thromboxane receptor and can be activated by $\mathrm{TxA}_{2}$ [39]. One hypothetic mechanism would be that $\mathrm{TxA}_{2}$ directly activate $\mathrm{CD} 4^{+} \mathrm{T}$ cells, while ASA is able to reduce this activation. However, the thromboxane and prostacyclin systems also regulate the interactions of platelets with endothelial cells in the vessel wall, and ASA is known to repeal endothelial dysfunction [40-43]. Endothelial cells are able to produce prostacyclin, an effective vasodilator and inhibitor of platelet activation as well as aggregation [44-46], whereas platelets synthesize $\mathrm{TxA}_{2}$, a vasoconstrictor and platelet aggregator [47-49]. There is also some evidence that endothelial cells are able to produce $\mathrm{TxA}_{2}$, although this is still controversial [50-52]. Therefore, another hypothesis of possible mechanisms of the reduced recruitment of $\mathrm{CD}^{+} \mathrm{T}$ cells would be altered activation of endothelial cells by $\mathrm{TxA}_{2}$ and ASA.

The development of EAE is dependent on the timing of platelet depletion [6], and not only prophylactic but also therapeutic treatment with low-dose ASA demonstrated a reduction in EAE symptoms. In addition, it is widely accepted that autoreactive $\mathrm{T}$ cells generated in the periphery migrate across the BBB, inducing disseminated inflammatory lesions within the brain parenchyma, leading to demyelination. Therefore, a prophylactic treatment might influence this early lymphocytic activation in contrast to a therapeutic application. Subsequently, prophylactic ASA treatment may thereby reduce immune cell infiltration into the CNS, explaining the more pronounced amelioration of the EAE clinical course compared to therapeutic application.

Since PF4 is a proinflammatory platelet alpha-granule protein and plasma levels of PF4 are significantly increased in MS patients compared to healthy control [37], we investigated plasma PF4 level changes during neuroinflammation. However, no difference in PF4 levels was found between ASA- and vehicle-treated mice or between naive and EAE mice. In agreement with our data, Cananzi et al. demonstrated PF4 levels were not affected by ASA treatment in MS patients [37]. GPVI is one of the most essential platelet collagen receptors involved in atherothrombosis, and soluble GPVI is rapidly proteolytically cleaved by $\mathrm{TxA}_{2}$-induced MMP $[38,53]$. Since GPVI expression is restricted to platelets and megakaryocytes, it is another potential antithrombotic target [54,55], and in line, patients with a GPVI deficiency do not exhibit symptoms other than a mild bleeding tendency [56-63]. In the present study, the reduction of soluble GPVI plasma levels was not found in low-dose ASA-treated mice compared to control mice.

Interestingly, a promising difference was found between naïve and EAE mice: Soluble GPVI plasma levels were increased during the EAE disease course compared to naïve mice, suggesting an important role of GPVI for platelets during neuroinflammation. In contrast to high-dose ASA, GPVI antagonistic agents do not lead to increased bleeding risk, making GPVI, in addition to low-dose ASA, a promising target in antiplatelet therapy [64]. However, we detected only a minor amelioration of EAE symptoms in GPVI deficient mice. Kleinschnitz et al. addressed the involvement of GPIb and GPVI in experimental stroke and found that the blockade of these receptors results in a reduction of the infarct size, with the effect induced by a GPVI blockade not as pronounced as the inhibition of GPIb. In addition, anti-GPVI-treated mice showed a better neurological outcome. However, the difference did 
not reach statistical significance [53]. Targeting GPVI is clearly a less compelling treatment strategy for autoimmune neuroinflammation, as it is a less effective abrogator of the neuroinflammatory response. Since GPVI acts as a platelet activation receptor, its function might be compensated by alternative pathways, such as G-protein-mediated signaling pathways [65]. A comparative study discovered that a combined approach, including both GPVI inhibition and ASA treatment, leads to an additional decrease of plaque-induced platelet aggregation in vitro [66]. Therefore, combination therapy of GPVI blockade and ASA could be a promising therapeutic approach to investigate in EAE. However, one should keep in mind that $\mathrm{TxA}_{2}$ is required for hemostasis in GPVI-deficient mice, which could cause significantly prolonged bleeding times [65].

The reduction in inflammatory infiltrates in ASA-treated mice raises the question if the interaction between platelets and lymphocytes is direct or indirect. The interaction between platelets and lymphocytes might lead to the production of signaling molecule production between these cells. In the present study, we focused on the platelet-mediated impact on neuroinflammation, but further experiments could address the complex interaction of platelets and lymphocytes by measuring, for example, differences in CD40L, CD62P or first procaspase activating compound- 1 levels, as well as platelet-lymphocyte aggregates following ASA treatment $[8,67]$.

In summary, additional studies are needed to further reveal the underlying mechanisms of platelet inhibition by low-dose ASA during neuroinflammatory processes. Overall, our findings show that the inhibition of platelet activation via low-dose ASA is beneficial in an animal model of MS, indicating a potential antithrombotic strategy to combat MS.

\section{Materials and Methods}

\subsection{Study Approval}

All animal experiments were conducted in accordance with the local animal ethics committee in North Rhine-Westphalia, Germany (81-02.04.2018.A382, approval date: 8 February 2019; 84-02.04.2013.A142, approval date: 16 October 2013) and the ARRIVE (Animal Research: Reporting of In Vivo Experiments) guidelines [68].

\subsection{Mice}

C57BL/6J mice were obtained from Charles River Laboratories (Sulzfeld, Germany), and $\mathrm{GPVI}^{-/-}$were generated as previously described [69]. Mice were kept in individually ventilated cages under standard conditions. Male and female, 8-15-week-old mice were used for immunization, and all animals had access to food as well as water ad libitum.

\subsection{EAE Induction}

For active EAE induction, mice were immunized with $200 \mu \mathrm{g} \mathrm{MOG}_{35-55}$ peptide (peptide sequence MEVGWYRSPFSRVVHLYRNGK; Charité-University Hospital Berlin, Germany) dissolved in $200 \mu \mathrm{L}$ complete Freund's adjuvant (Merck KGaA, Darmstadt, Germany). Complete Freund's adjuvant including $200 \mu \mathrm{g}$ Mycobacterium tuberculosis (strain H37 R $\alpha$; Becton, Dickinson and Company (BD), Sparks, United States of America (USA)) and $100 \mu \mathrm{L} \mathrm{MOG}_{35-55}$ emulsion were administered into each flank proximal to the inguinal lymph nodes by subcutaneous injection under isoflurane anesthesia. On the day of immunization and two days later, $100 \mathrm{ng}$ pertussis toxin (lot number 1007 with potency 1.5; Hooke Laboratories Inc., Lawrence, KS, USA) diluted in $100 \mu \mathrm{L}$ Dulbecco's phosphatebuffered saline (DPBS; Merck KGaA) was injected intraperitoneally. Clinical symptoms of EAE were assessed daily in a blinded fashion by two independent observers and translated into clinical EAE scores: score 0: no detectable clinical signs; score 1: partially limp tail; score 2: paralyzed tail; score 3: moderate hindlimb weakness; score 4: complete hindlimb weakness; score 5: mild paraparesis of the hindlimbs; score 6: paraparesis, weakness in forelimbs; score 7: severe paraparesis or paraplegia; score 8: tetraparesis; score 9: quadriplegia or premoribund state; score 10: death. Mice with a score of $\geq 1$ for two consecutive days were included in the study. Animals with a score $>7$, with a score of 7 for more than 
4 consecutive days or with a weight loss of more than $20 \%$ of the initial body weight were excluded from the experiment to guarantee animal welfare, and their last observed score was assumed for the rest of the experiment. The cumulative score was calculated as the average of all daily scores for the whole period of the experiment.

\subsection{Treatment with ASA}

Mice were treated with $3 \mathrm{mg} / \mathrm{kg}$ BW ASA ( $\mathrm{ASA}_{\text {low }}$; Merck KGaA), $30 \mathrm{mg} / \mathrm{kg}$ BW ASA ( $\left(\mathrm{ASA}_{\text {high }}\right.$ ) or vehicle prophylactically (beginning at the day of immunization) or therapeutically (beginning at the day of disease onset (day 10)) once daily. ASA was dissolved in $0.5 \%$ carboxymethyl cellulose (CMC; Merck KGaA), and mice were gavaged with $500 \mu \mathrm{L}$ of ASA solution. Control mice were gavaged with $500 \mu \mathrm{L} 0.5 \% \mathrm{CMC}$ as vehicle.

\subsection{Immunohistochemistry}

After intensive transcardial perfusion of mice with DPBS at disease maximum (day 16), lumbar spinal cords were dissected in $10 \mu \mathrm{m}$-thin slices using a cryotome (Leica, Wetzlar, Germany). Sections were stained with hematoxylin and eosin (H\&E) to assess the extent of inflammation or FluoroMyelin green (1:300; Thermo Fisher, Waltham, MA, USA), for specific labeling of myelin. For the detection of activated microglia and macrophages, slices were fixed with $4 \%$ paraformaldehyde for $10 \mathrm{~min}$ at room temperature (RT), washed three times with PBS and blocked for $4 \mathrm{~h}$ at RT with PBS containing 5\% bovine serum albumin (BSA; Merck KGaA), $1 \%$ normal goat serum (NGS; Merck KGaA) and $0.3 \%$ Triton X-100 (Merck KGaA). Afterward, slices were incubated with the primary antibody (rabbit anti-mouse Iba-1; 1:1000, FUJIFILM Wako Pure Chemicals Corporation, Osaka, Japan) at $4{ }^{\circ} \mathrm{C}$ overnight. The primary antibody was diluted with PBS containing $5 \%$ BSA and $1 \%$ NGS. After washing, slices were covered with goat anti-rabbit Cy3 (1:400) for $1 \mathrm{~h}$ at RT. For testing autofluorescence of the samples as well as sensitivity and affinity of the used antibodies, negative controls were obtained, and no specific signal was detectable (not shown). Following final washing, sections were mounted with Fluoromount-G, including 4',6-diamidino-2-phenylindole (DAPI; Thermo Fisher). Stainings were examined by microscopy (Axiophot2, Zeiss, Oberkochen, Germany) and analyzed in a blinded manner using Image J software (National Institute of Mental Health, Bethesda, ML, USA). To assess the degree of neuroinflammation, inflammatory and demyelinated areas were quantified and presented as the percentage of total area. For the examination of activated microglia and macrophages, Iba- $1^{+}$cells were counted and presented as the number of positive cells per $\mathrm{mm}^{2}$ of EAE lesion. For each animal, the arithmetic mean was calculated from five randomly selected coverslips with at least 3 slices per coverslip.

\subsection{Immunological Assessment of EAE}

For the extraction of CNS infiltrating cells, spinal cords were harvested after intensive transcardial perfusion with DPBS. CNS tissues were mechanically homogenized in DPBS, layered on a 30-50\% Percoll (Merck KGaA) gradient and centrifuged for 30 min at $1200 \times g$ without using the brake. Calibrite beads (BD) were added before washing and staining for quantification of cell numbers isolated from the interphase. To assess the number of infiltrated platelets, CNS homogenates were centrifuged at $250 \times \mathrm{g}$ for $5 \mathrm{~min}$ at RT to receive platelet-rich supernatant. This supernatant was stained for CD41 (clone MWReg30, BioLegend, San Diego, CA, USA), as well as CD61 (clone 2C9.G2, BioLegend), and fixed with $1 \%$ PFA before evaluation. CNS infiltrating cells were stained with fluorochromeconjugated antibodies from BioLegend for CD3 (clone 17A2), CD4 (clone GK1.5), CD8a (clone 53-6.7), CD11b (clone M1/70), CD45R/B220 (clone RA3-6B2) and CD45 (clone 30F11). Corresponding isotype controls were used for all stainings and for blocking the $\mathrm{FC}_{\mathrm{C}}$ receptor binding; cells were preincubated with an anti-CD16/CD32 antibody (BioLegend) for $5 \mathrm{~min}$ on ice. The stained samples were analyzed using a multi-color flow cytometer (Gallios, Beckman Coulter, Krefeld, Germany) and Kaluza software (Beckman Coulter). Cell doublets were excluded to ensure single cell counting. 


\subsection{Quantification of Soluble Analytes}

The retrobulbar murine blood was collected and centrifuged at $2200 \times g$ for $10 \mathrm{~min}$ to obtain blood plasma. Thromboxane B2 (Elabscience, Houston, TX, USA), PF4 (Merck KGaA) and GPVI (LSBio, Seattle, WA, USA) were quantified using enzyme-linked immunosorbent assays in blood plasma samples following the manufacturer's recommendations.

\subsection{Statistical Analysis}

For each type of experiment, group sizes are given in the figure legends and data are presented as the mean \pm standard error of the mean. No data outliers were excluded. For comparison of EAE scores between groups, a two-way analysis of variance (ANOVA) was performed, followed by a Bonferroni post-hoc test. D'Agostino-Pearson omnibus was used to assess the normality of a dataset. In the case of multiple comparisons, KruskalWallis test with Dunn post hoc analysis was used. Otherwise, pairwise comparisons between groups were conducted using the Mann-Whitney U-test. Data were analyzed using Prism 5.04 (GraphPad Software, San Diego, CA, USA), and values of probability $p<0.05$ were considered statistically significant. The level of significance was labeled as NS (not significant), ${ }^{*} p<0.05,{ }^{* *} p<0.01$ or ${ }^{* * *} p<0.001$.

Supplementary Materials: The following are available online at https://www.mdpi.com/article/10 .3390/ijms22189915/s1.

Author Contributions: Conceptualization, A.V., S.E., K.G. and S.G.M.; methodology, A.V., S.E., N.H., L.M., H.B., L.S., K.L., B.N., B.E.K. and K.G.; validation, A.V., S.E. and S.G.M.; formal analysis, A.V., S.E., N.H., L.M., K.G. and S.G.M.; investigation, A.V., S.E., N.H., L.M., H.B. and L.S.; resources, S.G.M.; data curation, A.V., S.E., N.H., L.M., H.B., L.S., A.W., K.L., B.N., B.E.K. and A.Z.; writing-original draft preparation, A.V., S.E. and S.G.M.; writing-review and editing, A.V., S.E., N.H., L.M., H.B., L.S., A.W., K.L., B.N., B.E.K., A.Z., K.G. and S.G.M.; visualization, A.V. and S.E.; supervision, S.E. and S.G.M.; project administration, S.E. and S.G.M.; funding acquisition, S.G.M. All authors have read and agreed to the published version of the manuscript.

Funding: S.G.M. received honoraria for lecturing and travel reimbursement for attending meetings from Almirall, Amicus Therapeutics Germany, Bayer Health Care, Biogen, Celgene, Diamed, Genzyme, MedDay Pharmaceuticals, Merck Serono, Novartis, Novo Nordisk, ONO Pharma, Roche, Sanof-Aventis, Chugai Pharma, QuintilesIMS, and Teva. His research is funded by the German Ministry for Education and Research (BMBF), Bundesinstitut für Risikobewertung (BfR), Deutsche Forschungsgemeinschaft (DFG), Else Kröner Fresenius Foundation, Gemeinsamer Bundesausschuss (G-BA), German Academic Exchange Service, Hertie Foundation, Interdisciplinary Center for Clinical Studies (IZKF) Muenster, German Foundation Neurology and Alexion, Almirall, Amicus Therapeutics Germany, Biogen, Diamed, Fresenius Medical Care, Genzyme, HERZ Burgdorf, Merck Serono, Novartis, ONO Pharma, Roche, and Teva. All other authors received no funding and declare no conflict of interest.

Institutional Review Board Statement: The study was conducted according to the guidelines of the Declaration of Helsinki, and approved by the Institutional Review Board (or Ethics Committee) of Landesamt für Natur, Umwelt und Verbraucherschutz Nordrhein-Westfalen (81-02.04.2018.A382, approval date: 8 February 2019; 84-02.04.2013.A142, approval date: 16 October 2013).

Informed Consent Statement: Not applicable.

Acknowledgments: The authors would like to thank Carina Butz and Frank Schmelter for excellent technical assistance. We are grateful to Heike Blum for illustrating Figure 1A.

Conflicts of Interest: The authors declare no conflict of interest.

\section{References}

1. Coetzee, T.; Thompson, A.J. Atlas of MS 2020: Informing global policy change. Mult. Scler. Houndmills Basingstoke Engl. 2020, 26, 1807-1808. [CrossRef]

2. Hirtz, D.; Thurman, D.J.; Gwinn-Hardy, K.; Mohamed, M.; Chaudhuri, A.R.; Zalutsky, R. How common are the "common" neurologic disorders? Neurology 2007, 68, 326-337. [CrossRef] 
3. Lucchinetti, C.F.; Popescu, B.F.G.; Bunyan, R.F.; Moll, N.M.; Roemer, S.F.; Lassmann, H.; Brück, W.; Parisi, J.E.; Scheithauer, B.W.; Giannini, C.; et al. Inflammatory cortical demyelination in early multiple sclerosis. N. Engl. J. Med. 2011, 365, $2188-2197$. [CrossRef]

4. Cree, B.A.C.; Mares, J.; Hartung, H.-P. Current therapeutic landscape in multiple sclerosis: An evolving treatment paradigm. Curr. Opin. Neurol. 2019, 32, 365-377. [CrossRef]

5. Dargahi, N.; Katsara, M.; Tselios, T.; Androutsou, M.-E.; de Courten, M.; Matsoukas, J.; Apostolopoulos, V. Multiple Sclerosis: Immunopathology and Treatment Update. Brain Sci. 2017, 7, 78. [CrossRef]

6. $\quad$ Langer, H.F.; Choi, E.Y.; Zhou, H.; Schleicher, R.; Chung, K.-J.; Tang, Z.; Göbel, K.; Bdeir, K.; Chatzigeorgiou, A.; Wong, C.; et al. Platelets contribute to the pathogenesis of experimental autoimmune encephalomyelitis. Circ. Res. 2012, 110, 1202-1210. [CrossRef]

7. Sotnikov, I.; Veremeyko, T.; Starossom, S.C.; Barteneva, N.; Weiner, H.L.; Ponomarev, E.D. Platelets recognize brain-specific glycolipid structures, respond to neurovascular damage and promote neuroinflammation. PLoS ONE 2013, 8, e58979. [CrossRef]

8. Starossom, S.C.; Veremeyko, T.; Yung, A.W.Y.; Dukhinova, M.; Au, C.; Lau, A.Y.; Weiner, H.L.; Ponomarev, E.D. Platelets Play Differential Role During the Initiation and Progression of Autoimmune Neuroinflammation. Circ. Res. 2015, 117, 779-792. [CrossRef]

9. Sonia D’Souza, C.; Li, Z.; Luke Maxwell, D.; Trusler, O.; Murphy, M.; Crewther, S.; Peter, K.; Orian, J.M. Platelets Drive Inflammation and Target Gray Matter and the Retina in Autoimmune-Mediated Encephalomyelitis. J. Neuropathol. Exp. Neurol. 2018, 77, 567-576. [CrossRef]

10. Kocovski, P.; Jiang, X.; D’Souza, C.S.; Li, Z.; Dang, P.T.; Wang, X.; Chen, W.; Peter, K.; Hale, M.W.; Orian, J.M. Platelet Depletion is Effective in Ameliorating Anxiety-Like Behavior and Reducing the Pro-Inflammatory Environment in the Hippocampus in Murine Experimental Autoimmune Encephalomyelitis. J. Clin. Med. 2019, 8, 162. [CrossRef]

11. Lock, C.; Hermans, G.; Pedotti, R.; Brendolan, A.; Schadt, E.; Garren, H.; Langer-Gould, A.; Strober, S.; Cannella, B.; Allard, J.; et al. Gene-microarray analysis of multiple sclerosis lesions yields new targets validated in autoimmune encephalomyelitis. Nat. Med. 2002, 8, 500-508. [CrossRef] [PubMed]

12. Sheremata, W.A.; Jy, W.; Horstman, L.L.; Ahn, Y.S.; Alexander, J.S.; Minagar, A. Evidence of platelet activation in multiple sclerosis. J. Neuroinflamm. 2008, 5, 27. [CrossRef]

13. Bijak, M.; Olejnik, A.; Rokita, B.; Morel, A.; Dziedzic, A.; Miller, E.; Saluk-Bijak, J. Increased level of fibrinogen chains in the proteome of blood platelets in secondary progressive multiple sclerosis patients. J. Cell. Mol. Med. 2019, 23, 3476-3482. [CrossRef]

14. Dziedzic, A.; Miller, E.; Bijak, M.; Przyslo, L.; Saluk-Bijak, J. Increased Pro-Thrombotic Platelet Activity Associated with Thrombin/PAR1-Dependent Pathway Disorder in Patients with Secondary Progressive Multiple Sclerosis. Int. J. Mol. Sci. 2020, 21, 7722. [CrossRef]

15. Brønnum-Hansen, H.; Koch-Henriksen, N.; Stenager, E. Trends in survival and cause of death in Danish patients with multiple sclerosis. Brain J. Neurol. 2004, 127, 844-850. [CrossRef] [PubMed]

16. Christensen, S.; Farkas, D.K.; Pedersen, L.; Miret, M.; Christiansen, C.F.; Sørensen, H.T. Multiple sclerosis and risk of venous thromboembolism: A population-based cohort study. Neuroepidemiology 2012, 38, 76-83. [CrossRef] [PubMed]

17. Christiansen, C.F.; Christensen, S.; Farkas, D.K.; Miret, M.; Sørensen, H.T.; Pedersen, L. Risk of arterial cardiovascular diseases in patients with multiple sclerosis: A population-based cohort study. Neuroepidemiology 2010, 35, 267-274. [CrossRef]

18. Pulcinelli, F.M.; Pignatelli, P.; Celestini, A.; Riondino, S.; Gazzaniga, P.P.; Violi, F. Inhibition of platelet aggregation by aspirin progressively decreases in long-term treated patients. J. Am. Coll. Cardiol. 2004, 43, 979-984. [CrossRef]

19. Pedersen, A.K.; FitzGerald, G.A. Dose-related kinetics of aspirin. Presystemic acetylation of platelet cyclooxygenase. N. Engl. J. Med. 1984, 311, 1206-1211. [CrossRef]

20. Budd, J.S.; Allen, K.; Walsh, A.; Bell, P.R. The effectiveness of low dose slow release aspirin as an antiplatelet agent. J. R. Soc. Med. 1993, 86, 261-263.

21. Antithrombotic Trialists' Collaboration. Collaborative meta-analysis of randomised trials of antiplatelet therapy for prevention of death, myocardial infarction, and stroke in high risk patients. BMJ 2002, 324, 71-86. [CrossRef]

22. CURRENT-OASIS 7 Investigators; Mehta, S.R.; Bassand, J.-P.; Chrolavicius, S.; Diaz, R.; Eikelboom, J.W.; Fox, K.A.A.; Granger, C.B.; Jolly, S.; Joyner, C.D.; et al. Dose comparisons of clopidogrel and aspirin in acute coronary syndromes. N. Engl. J. Med. 2010, 363, 930-942. [CrossRef]

23. Mehta, S.R.; Tanguay, J.-F.; Eikelboom, J.W.; Jolly, S.S.; Joyner, C.D.; Granger, C.B.; Faxon, D.P.; Rupprecht, H.-J.; Budaj, A.; Avezum, A.; et al. Double-dose versus standard-dose clopidogrel and high-dose versus low-dose aspirin in individuals undergoing percutaneous coronary intervention for acute coronary syndromes (CURRENT-OASIS 7): A randomised factorial trial. Lancet Lond. Engl. 2010, 376, 1233-1243. [CrossRef]

24. FitzGerald, G.A.; Oates, J.A.; Hawiger, J.; Maas, R.L.; Roberts, L.J.; Lawson, J.A.; Brash, A.R. Endogenous biosynthesis of prostacyclin and thromboxane and platelet function during chronic administration of aspirin in man. J. Clin. Investig. 1983, 71, 676-688. [CrossRef]

25. Undas, A.; Brummel, K.; Musial, J.; Mann, K.G.; Szczeklik, A. Blood coagulation at the site of microvascular injury: Effects of low-dose aspirin. Blood 2001, 98, 2423-2431. [CrossRef]

26. He, S.; Blombäck, M.; Yoo, G.; Sinha, R.; Henschen-Edman, A.H. Modified clotting properties of fibrinogen in the presence of acetylsalicylic acid in a purified system. Ann. N. Y. Acad. Sci. 2001, 936, 531-535. [CrossRef] [PubMed] 
27. Santilli, F.; Davì, G.; Consoli, A.; Cipollone, F.; Mezzetti, A.; Falco, A.; Taraborelli, T.; Devangelio, E.; Ciabattoni, G.; Basili, S.; et al. Thromboxane-dependent CD40 ligand release in type 2 diabetes mellitus. J. Am. Coll. Cardiol. 2006, 47, 391-397. [CrossRef] [PubMed]

28. Nannizzi-Alaimo, L.; Alves, V.L.; Phillips, D.R. Inhibitory effects of glycoprotein IIb/IIIa antagonists and aspirin on the release of soluble CD40 ligand during platelet stimulation. Circulation 2003, 107, 1123-1128. [CrossRef]

29. Masuda, H.; Mori, M.; Uchida, T.; Uzawa, A.; Ohtani, R.; Kuwabara, S. Soluble CD40 ligand contributes to blood-brain barrier breakdown and central nervous system inflammation in multiple sclerosis and neuromyelitis optica spectrum disorder. $J$. Neuroimmunol. 2017, 305, 102-107. [CrossRef] [PubMed]

30. Sanchooli, J.; Ramroodi, N.; Sanadgol, N.; Sarabandi, V.; Ravan, H.; Rad, R.S. Relationship between metalloproteinase 2 and 9 concentrations and soluble CD154 expression in Iranian patients with multiple sclerosis. Kaohsiung J. Med. Sci. 2014, 30, $235-242$. [CrossRef]

31. Zabaleta, M.; Marino, R.; Borges, J.; Camargo, B.; Ordaz, P.; De Sanctis, J.B.; Bianco, N.E. Activity profile in multiple sclerosis: An integrative approach. A preliminary report. Mult. Scler. Houndmills Basingstoke Engl. 2002, 8, 343-349. [CrossRef]

32. Good, R.A.; Campbell, B.; Good, T.A. Prophylactic and therapeutic effect of para-aminobenzoic acid and sodium salicylate on experimental allergic encephalomyelitis. Exp. Biol. Med. 1949, 72, 341-347. [CrossRef]

33. Moon, C.; Ahn, M.; Jee, Y.; Heo, S.; Kim, S.; Kim, H.; Sim, K.-B.; Koh, C.-S.; Shin, Y.-G.; Shin, T. Sodium salicylate-induced amelioration of experimental autoimmune encephalomyelitis in Lewis rats is associated with the suppression of inducible nitric oxide synthase and cyclooxygenases. Neurosci. Lett. 2004, 356, 123-126. [CrossRef]

34. Mondal, S.; Jana, M.; Dasarathi, S.; Roy, A.; Pahan, K. Aspirin ameliorates experimental autoimmune encephalomyelitis through interleukin-11-mediated protection of regulatory T cells. Sci. Signal. 2018, 11, 558. [CrossRef] [PubMed]

35. Marusic, S.; Thakker, P.; Pelker, J.W.; Stedman, N.L.; Lee, K.L.; McKew, J.C.; Han, L.; Xu, X.; Wolf, S.F.; Borey, A.J.; et al. Blockade of cytosolic phospholipase A2 alpha prevents experimental autoimmune encephalomyelitis and diminishes development of Th1 and Th17 responses. J. Neuroimmunol. 2008, 204, 29-37. [CrossRef] [PubMed]

36. Rossi, B.; Constantin, G. Live Imaging of Immune Responses in Experimental Models of Multiple Sclerosis. Front. Immunol. 2016, 7, 506. [CrossRef] [PubMed]

37. Cananzi, A.R.; Ferro-Milone, F.; Grigoletto, F.; Toldo, M.; Meneghini, F.; Bortolon, F.; D'Andrea, G. Relevance of platelet factor four (PF4) plasma levels in multiple sclerosis. Acta Neurol. Scand. 1987, 76, 79-85. [CrossRef]

38. Bergmeier, W.; Rabie, T.; Strehl, A.; Piffath, C.L.; Prostredna, M.; Wagner, D.D.; Nieswandt, B. GPVI down-regulation in murine platelets through metalloproteinase-dependent shedding. Thromb. Haemost. 2004, 91, 951-958. [CrossRef]

39. Kabashima, K.; Murata, T.; Tanaka, H.; Matsuoka, T.; Sakata, D.; Yoshida, N.; Katagiri, K.; Kinashi, T.; Tanaka, T.; Miyasaka, M.; et al. Thromboxane A2 modulates interaction of dendritic cells and T cells and regulates acquired immunity. Nat. Immunol. 2003, 4, 694-701. [CrossRef] [PubMed]

40. Zucker, T.P.; Bönisch, D.; Muck, S.; Weber, A.A.; Bretschneider, E.; Glusa, E.; Schrör, K. Thromboxane A2 potentiates thrombininduced proliferation of coronary artery smooth muscle cells. Adv. Exp. Med. Biol. 1997, 433, 387-390. [CrossRef] [PubMed]

41. FitzGerald, G.A.; Smith, B.; Pedersen, A.K.; Brash, A.R. Increased prostacyclin biosynthesis in patients with severe atherosclerosis and platelet activation. N. Engl. J. Med. 1984, 310, 1065-1068. [CrossRef] [PubMed]

42. Husain, S.; Andrews, N.P.; Mulcahy, D.; Panza, J.A.; Quyyumi, A.A. Aspirin improves endothelial dysfunction in atherosclerosis Circulation 1998, 97, 716-720. [CrossRef]

43. Monobe, H.; Yamanari, H.; Nakamura, K.; Ohe, T. Effects of low-dose aspirin on endothelial function in hypertensive patients. Clin. Cardiol. 2001, 24, 705-709. [CrossRef]

44. Moncada, S.; Gryglewski, R.; Bunting, S.; Vane, J.R. An enzyme isolated from arteries transforms prostaglandin endoperoxides to an unstable substance that inhibits platelet aggregation. Nature 1976, 263, 663-665. [CrossRef]

45. Moncada, S.; Herman, A.G.; Higgs, E.A.; Vane, J.R. Differential formation of prostacyclin (PGX or PGI2) by layers of the arterial wall. An explanation for the anti-thrombotic properties of vascular endothelium. Thromb. Res. 1977, 11, 323-344. [CrossRef]

46. MacIntyre, D.E.; Pearson, J.D.; Gordon, J.L. Localisation and stimulation of prostacyclin production in vascular cells. Nature 1978, 271, 549-551. [CrossRef] [PubMed]

47. Ho, P.P.; Walters, C.P.; Hermann, R.G. Synthesis of platelet-aggregating factor by human platelet microsomes. Biochem. Biophys. Res. Commun. 1976, 69, 218-224. [CrossRef]

48. Needleman, P.; Moncada, S.; Bunting, S.; Vane, J.R.; Hamberg, M.; Samuelsson, B. Identification of an enzyme in platelet microsomes which generates thromboxane A2 from prostaglandin endoperoxides. Nature 1976, 261, 558-560. [CrossRef]

49. Yoshimoto, T.; Yamamoto, S.; Okuma, M.; Hayaishi, O. Solubilization and resolution of thromboxane synthesizing system from microsomes of bovine blood platelets. J. Biol. Chem. 1977, 252, 5871-5874. [CrossRef]

50. Ingerman-Wojenski, C.; Silver, M.J.; Smith, J.B.; Macarak, E. Bovine endothelial cells in culture produce thromboxane as well as prostacyclin. J. Clin. Investig. 1981, 67, 1292-1296. [CrossRef]

51. Salzman, P.M.; Salmon, J.A.; Moncada, S. Prostacyclin and thromboxane A2 synthesis by rabbit pulmonary artery. J. Pharmacol. Exp. Ther. 1980, 215, 240-247. [PubMed]

52. Caughey, G.E.; Cleland, L.G.; Gamble, J.R.; James, M.J. Up-regulation of endothelial cyclooxygenase-2 and prostanoid synthesis by platelets. Role of thromboxane A2. J. Biol. Chem. 2001, 276, 37839-37845. [CrossRef] 
53. Kleinschnitz, C.; Pozgajova, M.; Pham, M.; Bendszus, M.; Nieswandt, B.; Stoll, G. Targeting platelets in acute experimental stroke: Impact of glycoprotein $\mathrm{Ib}, \mathrm{VI}$, and IIb/IIIa blockade on infarct size, functional outcome, and intracranial bleeding. Circulation 2007, 115, 2323-2330. [CrossRef] [PubMed]

54. Lagrue-Lak-Hal, A.H.; Debili, N.; Kingbury, G.; Lecut, C.; Le Couedic, J.P.; Villeval, J.L.; Jandrot-Perrus, M.; Vainchenker, W. Expression and function of the collagen receptor GPVI during megakaryocyte maturation. J. Biol. Chem. 2001, 276, 15316-15325. [CrossRef] [PubMed]

55. Jandrot-Perrus, M.; Busfield, S.; Lagrue, A.H.; Xiong, X.; Debili, N.; Chickering, T.; Le Couedic, J.P.; Goodearl, A.; Dussault, B.; Fraser, C.; et al. Cloning, characterization, and functional studies of human and mouse glycoprotein VI: A platelet-specific collagen receptor from the immunoglobulin superfamily. Blood 2000, 96, 1798-1807. [CrossRef]

56. Sugiyama, T.; Okuma, M.; Ushikubi, F.; Sensaki, S.; Kanaji, K.; Uchino, H. A novel platelet aggregating factor found in a patient with defective collagen-induced platelet aggregation and autoimmune thrombocytopenia. Blood 1987, 69, 1712-1720. [CrossRef]

57. Takahashi, H.; Moroi, M. Antibody against platelet membrane glycoprotein VI in a patient with systemic lupus erythematosus. Am. J. Hematol. 2001, 67, 262-267. [CrossRef]

58. Boylan, B.; Chen, H.; Rathore, V.; Paddock, C.; Salacz, M.; Friedman, K.D.; Curtis, B.R.; Stapleton, M.; Newman, D.K.; Kahn, M.L.; et al. Anti-GPVI-associated ITP: An acquired platelet disorder caused by autoantibody-mediated clearance of the GPVI/FcRgamma-chain complex from the human platelet surface. Blood 2004, 104, 1350-1355. [CrossRef] [PubMed]

59. Nurden, P.; Tandon, N.; Takizawa, H.; Couzi, L.; Morel, D.; Fiore, M.; Pillois, X.; Loyau, S.; Jandrot-Perrus, M.; Nurden, A.T. An acquired inhibitor to the GPVI platelet collagen receptor in a patient with lupus nephritis. J. Thromb. Haemost. 2009, 7, 1541-1549. [CrossRef] [PubMed]

60. Moroi, M.; Jung, S.M.; Okuma, M.; Shinmyozu, K. A patient with platelets deficient in glycoprotein VI that lack both collageninduced aggregation and adhesion. J. Clin. Investig. 1989, 84, 1440-1445. [CrossRef] [PubMed]

61. Dumont, B.; Lasne, D.; Rothschild, C.; Bouabdelli, M.; Ollivier, V.; Oudin, C.; Ajzenberg, N.; Grandchamp, B.; Jandrot-Perrus, M. Absence of collagen-induced platelet activation caused by compound heterozygous GPVI mutations. Blood 2009, 114, 1900-1903. [CrossRef]

62. Hermans, C.; Wittevrongel, C.; Thys, C.; Smethurst, P.A.; Van Geet, C.; Freson, K. A compound heterozygous mutation in glycoprotein VI in a patient with a bleeding disorder. J. Thromb. Haemost. 2009, 7, 1356-1363. [CrossRef] [PubMed]

63. Kehrel, B.; Wierwille, S.; Clemetson, K.J.; Anders, O.; Steiner, M.; Knight, C.G.; Farndale, R.W.; Okuma, M.; Barnes, M.J. Glycoprotein VI is a major collagen receptor for platelet activation: It recognizes the platelet-activating quaternary structure of collagen, whereas CD36, glycoprotein IIb/IIIa, and von Willebrand factor do not. Blood 1998, 91, 491-499. [CrossRef] [PubMed]

64. Penz, S.; Reininger, A.J.; Brandl, R.; Goyal, P.; Rabie, T.; Bernlochner, I.; Rother, E.; Goetz, C.; Engelmann, B.; Smethurst, P.A.; et al. Human atheromatous plaques stimulate thrombus formation by activating platelet glycoprotein VI. FASEB J. 2005, 19, 898-909. [CrossRef]

65. Grüner, S.; Prostredna, M.; Aktas, B.; Moers, A.; Schulte, V.; Krieg, T.; Offermanns, S.; Eckes, B.; Nieswandt, B. Anti-glycoprotein VI treatment severely compromises hemostasis in mice with reduced alpha2beta1 levels or concomitant aspirin therapy. Circulation 2004, 110, 2946-2951. [CrossRef]

66. Mojica Muñoz, A.-K.; Jamasbi, J.; Uhland, K.; Degen, H.; Münch, G.; Ungerer, M.; Brandl, R.; Megens, R.; Weber, C.; Lorenz, R.; et al. Recombinant GPVI-Fc added to single or dual antiplatelet therapy in vitro prevents plaque-induced platelet thrombus formation. Thromb. Haemost. 2017, 117, 1651-1659. [CrossRef] [PubMed]

67. Pankratz, S.; Bittner, S.; Kehrel, B.E.; Langer, H.F.; Kleinschnitz, C.; Meuth, S.G.; Göbel, K. The Inflammatory Role of Platelets: Translational Insights from Experimental Studies of Autoimmune Disorders. Int. J. Mol. Sci. 2016, 17, 1723. [CrossRef]

68. Percie du Sert, N.; Hurst, V.; Ahluwalia, A.; Alam, S.; Avey, M.T.; Baker, M.; Browne, W.J.; Clark, A.; Cuthill, I.C.; Dirnagl, U.; et al. The ARRIVE guidelines 2.0: Updated guidelines for reporting animal research. PLoS Biol. 2020, 18, e3000410. [CrossRef]

69. Bender, M.; May, F.; Lorenz, V.; Thielmann, I.; Hagedorn, I.; Finney, B.A.; Vögtle, T.; Remer, K.; Braun, A.; Bösl, M.; et al. Combined in vivo depletion of glycoprotein VI and C-type lectin-like receptor 2 severely compromises hemostasis and abrogates arterial thrombosis in mice. Arter. Thromb. Vasc. Biol. 2013, 33, 926-934. [CrossRef] 